\title{
Primaire preventie van overgewicht: gevoelige leeftijdsintervallen en predictie. Het Terneuzen Geboorte Cohort
}

In het Terneuzen Onderzoek naar Preventie zijn overgewicht en cardiometabole risicofactoren op jongvolwassen leeftijd bestudeerd in relatie tot de veranderingen in body mass index (BMI) tussen de geboorte en 18-jarige leeftijd. Deze studie is gebaseerd op het Terneuzen Geboorte Cohort, waarbij prospectief verkregen gegevens zijn verkregen via de jeugdgezondheidszorg (JGZ) van GGD Zeeland. Bij de analyses is gebruik gemaakt van de brokenstickmethode en van lineaire en logistische regressieanalyses. Het leeftijdsinterval 2-6 jaar was het meest voorspellend voor overgewicht en de meeste cardiometabole uitkomsten op jongvolwassen leeftijd. Deze resultaten vragen speciale aandacht van de JGZ voor een stijgende BMI-standaarddeviatiescore (SDS) gedurende het leeftijdsinterval 2-6 jaar, ook als er nog geen sprake is van overgewicht. Hierbij kunnen predictie-instrumenten nuttig zijn. Het monitoren en stabiliseren van de BMI SDS gedurende dit leeftijdsinterval draagt waarschijnlijk niet alleen bij aan de preventie van overgewicht op jongvolwassen leeftijd, maar ook aan een goede cardiometabole gezondheidstoestand op latere leeftijd.

\section{Inleiding}

Wereldwijd zijn veel initiatieven genomen om overgewicht en obesitas te bestrijden. Helaas nemen de prevalenties van overgewicht en obesitas en de ermee samen hangende morbiditeit, met name diabetes type 2 en hart- en vaatziekten, nog steeds toe.,2 Ook uit de Vijfde Landelijke Groeistudie in Nederland, verricht in 2009, blijkt de prevalentie van overgewicht bij 2- tot 19-jarigen hoger te zijn dan 12 jaar tevoren, zoals vastgesteld met de Vierde Landelijke Groeistudie. ${ }^{3}$

Primaire preventie van overgewicht betreft het aanbieden van preventie vóórdat er sprake is van overgewicht; secundaire preventie betekent het aanbieden van een interventie op het moment dat er al overgewicht is. De jeugdgezondheidszorg (JGZ) speelt een belangrijke rol bij het aanbieden van secundaire preventie op individueel niveau, met name door het aanbieden van het Overbrug gingsplan, maar ook door verwijzingen naar de tweede lijn en/of naar zwaardere interventies. ${ }^{4}$ Van het Overbruggingsplan is alleen bij kinderen met een beperkte mate van overgewicht effect aangetoond. ${ }^{5}$

Deze resultaten en de beperkte effectiviteit van interventies gericht op kinderen met overgewicht, met name op de lange termijn, pleiten ervoor preventie in een zo vroeg mogelijk stadium aan te bieden, zo mogelijk al vóór het ontstaan van overgewicht.

Naast primaire preventie gericht op de hele populatie en op álle leeftijdsgroepen, ofwel universele preventie, zou primaire preventie ook gericht kunnen worden op kinde- ren met een verhoogd risico, zodat men kan spreken van geïndiceerde (dat wil zeggen: individueel gerichte) primaire preventie. Geïndiceerde primaire preventie kan een leemte vullen in het huidige zorgaanbod door de JGZ.

Wat de meest gevoelige groeiperioden zijn voor het ontstaan van overgewicht is onvoldoende bekend. Ook is er onvoldoende kennis om op basis van antropometrische metingen kinderen te selecteren die een verhoogd risico op het ontstaan van overgewicht en/of cátíndiometabole ziekten hebben. Met het Terneuzen Onderzoek naar Preventie is ernaar gestreefd deze leemtes in kennis te vullen.

De belangrijkste doelstelling van het promotieonderzoek uitgevoerd in Terneuzen was vast te stellen welke leeftijdsintervallen het meest gevoelig zijn voor het ontstaan van overgewicht en gerelateerde cardiometabole risicofactoren. ${ }^{6-9}$ Hiermee samenhangende vraagstellingen luidden: 1) Welk leeftijdsinterval is de vroegste en meest relevante kritische groeiperiode voor het ontstaan van overgewicht? 2) Welk leeftijdsinterval is het meest voorspellend voor het ontstaan van cardiometabool risico? 3) Kan op jonge leeftijd voorspeld worden welke kinderen een verhoogde kans hebben op overgewicht?

\section{Methoden}

Het beantwoorden van de onderzoeksvragen is gebaseerd op het Terneuzen Geboorte Cohort $(n=2604)$. $^{6-10}$

M.L.A. de Kroon, jeugdarts en epidemioloog en R.A. HiraSing, kinderarts-jeugdarts, hoogleraar jeugdgezondheidszorg, afdeling Sociale Geneeskunde, Vrije Universiteit medisch centrum, EMGO+-Instituut, Amsterdam. C.M. Renders, epidemioloog, Vrije Universiteit, afdeling Gezondheidswetenschappen, EMGO'-Instituut, Amsterdam.J.P. van Wouwe, kinderarts en S. van Buuren, statisticus, TNO, Leiden. Correspondentie: ml.dekroon@vumc.nl. 
Van alle kinderen die in 1977-1986 in Terneuzen zijn geboren, werden prospectief vanaf de geboorte tot de leeftijd van 6 maanden gegevens verzameld over de zuigelingenvoeding. Van 1701 personen werden bovendien de groeigegevens verkregen, die zijn vastgelegd door de consultatiebureaus en de JGZ van de GGD Zeeland. Deze personen werden vervolgens uitgenodigd om deel te nemen aan een vervolgonderzoek in 2004 2005 , dat bestond uit afname van schriftelijke vragenlijsten, antropometrische metingen en bloedtests.

Bij het beantwoorden van de 3 vraagstellingen zijn van 762 personen van het Terneuzen Cohort gegevens gebruikt. Van hen zijn tussen geboorte en jongvolwassen leeftijd gemiddeld 21 metingen van lengte en gewicht vastgelegd. Op jongvolwassen leeftijd zijn bij hen meerdere antropometrische metingen verricht en bij 642 van hen is eveneens nuchter bloed afgenomen. ${ }^{10}$ De uitkomstmaten op jongvolwassen leeftijd waren de BMI-standaarddeviatiescore (SDS), middelomtrek, huidplooidikte, bloeddruk, en de bloedwaarden van HDLcholesterol, triglyceriden, hooggevoelige C-reactief proteine (hsCRP) en nuchtere glucose, of - indien de uitkomsten niet normaal verdeeld waren - de logwaarden van deze uitkomsten. De onafhankelijke variabelen waren de BMI SDS- en conditionele BMI SDS-waarden op bepaalde leeftijden, die op basis van literatuuronderzoek zijn gekozen. ${ }^{6}$ Een conditionele BMI SDS-waarde is dat deel van de BMI SDS-waarde op een bepaalde leeftijd dat statistisch niet verklaard kan worden door de BMI SDSwaarden op eerdere leeftijden. De gekozen leeftijden waren o jaar, 4 maanden, 1 jaar, 2 jaar, 6 jaar, 10 jaar en 18 jaar. De BMI SDS-waarden op deze leeftijden zijn geschat door het fitten van individuele BMI SDS-curves met behulp van de brokenstickmethode. ${ }^{7}$

Vervolgens is met $t$-toetsen, Pearsons correlatietests, multipele lineaire en (backwards) logistische (conditionele) regressie bepaald gedurende welke leeftijdsintervallen BMI SDS-veranderingen het meest voorspellend waren voor de uitkomsten op jongvolwassen leeftijd. Er is voor meerdere covariaten en confounders gecorrigeerd, zoals leeftijd, geslacht, BMI van de moeder en opleidingsniveau. De interne validiteit van de ontwikkelde voorspellingsmodellen is getoetst met de bootstrapprocedure. Met ROC-analyses zijn sensitiviteit en specificiteit berekend.

Bij de statistische analyses werd gebruik gemaakt van S Plus 8.0 en SPSS 14.0 ,

\section{Resultaten}

De ontwikkeling van de BMI SDS gedurende het leeftijdsinterval 2-6 jaar was het meest voorspellend voor de BMI SDS op jongvolwassen leeftijd in vergelijking met andere leeftijdsintervallen. De verklaarde variantie in deze periode nam met $11 \%$ toe door het model dat de BMI SDS op 6-jarige leeftijd includeerde, uit te breiden met de BMI SDS op 2-jarige leeftijd. Voor andere intervallen lag deze toename tussen de o en $7 \%{ }^{7}$ Post-hocanalyses wezen uit dat de BMI-verandering gedurende het leeftijdsinterval 2-4 jaar ongeveer even sterk voorspellend was als de BMI-verandering gedurende het leeftijdsinterval 4-6 jaar.

Het leeftijdsinterval 2-6 jaar bleek voorspellend te zijn voor de meeste cardiometabole uitkomstmaten. Uitzondering vormt nuchtere glucose, dat met geen enkele BMI SDS-ontwikkeling een statistisch significant verband had. Het leeftijdsinterval 2-6 jaar was de sterkste voorspeller voor middelomtrek, huidplooidikte, bloeddruk en hsCRP. De ontwikkeling van het BMI SDS tussen de 10 en 18 jaar was de sterkste voorspeller voor HDL-cholesterol en triglyceriden. In tabel 1, een verkorte weergave van de oorspronkelijke tabel uit het artikel van MIA de Kroon uit 2010, staan voor de leeftijdsintervallen 2-6 jaar en 10-18 jaar de relaties weergegeven tot de cardiometabole uitkomsten op jongvolwassen leeftijd. ${ }^{8}$

Vervolgens is een voorspellingsmodel ontwikkeld op basis van de BMI SDS-ontwikkeling tussen de 2 en 6 jaar voor overgewicht op volwassen leeftijd (figuur 1 en 2). De voorspellingsmodellen hadden een hoge performance: de area under the curve (AUC) voor de leeftijdsintervallen 2-6 jaar en 2-4 jaar was respectievelijk o,83 (95\%-BI 0,78$0,88)$ en $0,79(95 \%-B I 0,73-0,85)$ voor jongens, en respectievelijk 0,80 (95\%-BI 0,75-0,84) en 0,76 (95\%-BI 0,71-o,81) voor meisjes. Volgens ROC-analyses is de gewenste afkapwaarde voor het risico op overgewicht op volwassen leeftijd rond de $25 \%$. In tabel 2 staan sensitiviteit, specificiteit en positief voorspellende waarden voor verschillende afkappunten van deze modellęn voor de leeftijdsintervallen 2-6 en 2-4 jaar weergegeven.

\section{Discussie en conclusies}

Uit ons onderzoek is gebleken dat de ontwikkeling van de BMI (SDS) tussen de 2 en 6 jaar het meest voorspellend is voor overgewicht op volwassen leeftijd. Tevens bleek dat de BMI SDS-ontwikkeling tussen 2 en 6 jaar ook de meeste andere cardiometabole uitkomsten op volwassen leeftijd meer en sterker voorspelde dan de BMI SDS-ontwikkeling gedurende de andere leeftijdsintervallen tussen de o en 18 jaar. Het leeftijdsinterval 10-18 jaar was echter het meest voorspellend voor de triglyceriden- en HDL-cholesterolgehaltes op jongvolwassen leeftijd. Tot slot bleek het mogelijk om voor het leeftijdsinterval 2-6 jaar op basis van BMI SDS en geslacht predictie-instrumenten met een hoge performance te ontwikkelen om overgewicht op jongvolwassen leeftijd te voorspellen.

In overeenstemming met andere studies bleek dat de groei gedurende bepaalde leeftijdsintervallen gevoeliger is dan die gedurende andere leeftijdsintervallen voor de ontwikkeling van overgewicht en cardiometabole risicofactoren. Hiervoor bestaat nog geen duidelijke verklaring. ${ }^{11-16}$ Mogelijk dat biologische mechanismen een rol spelen. ${ }^{17-21}$ Meerdere studies hebben uitgewezen dat 
Tabel i De resultaten voor de leeftijdsintervallen 2-6 jaar en 10-18 jaar van multipele lineaire en logistische regressiemodellen van cardiometabole uitkomsten op jongvolwassen leeftijd, met als onafhankelijke variabelen de conditionele BMi SDS-veranderingen voor de leeftijdsintervallen 0-1 jaar, 1-2 jaar, 2-6 jaar, 6-10 jaar en 10-18 jaar en de BMI SDS bij de geboorte.

\begin{tabular}{|c|c|c|c|c|c|c|c|}
\hline \multirow[t]{2}{*}{ witkomsten (insms) } & \multicolumn{6}{|c|}{ gestandardiserderenressiecogfichenten en $95 \% \mathrm{Bl}$} & \multirow{2}{*}{$\begin{array}{l}\text { verblakto } \\
\text { variantie }\end{array}$} \\
\hline & \multicolumn{3}{|c|}{$\begin{array}{l}\text { BMI SDS-verandermg } \\
\text { tusson z-6joar }\end{array}$} & \multicolumn{2}{|c|}{$\begin{array}{l}\text { BNU SDS-verandering } \\
\text { twssen } 10-18 \mathrm{jad} \text { b }\end{array}$} & & \\
\hline middelomtrek & 0,47 & $0,43-0,51$ & $\therefore *$ & 0,36 & $0,32-0,40$ & $"$ & 0,60 \\
\hline huidplooidikte & 0,38 & $0,32-0,44$ & *** & 0,33 & $0,29-0,37$ & *. & 0,56 \\
\hline systolische bloeddruk & 0,19 & $0,130,25$ & * & 0,11 & $0,05-0,17$ & $\cdots$ & 0,28 \\
\hline diastolische bloeddruk & 0,20 & $0,12-0,28$ & $\omega$ & 0,04 & $\cdots 0,02 \cdots 0,10$ & & 0,06 \\
\hline HDL-cholesterola & 008 & $016-000$ & $*$ & $-0,10$ & $:-0,16--0,04$ & $*$ & 0,18 \\
\hline triglyceridena & 0,18 & $0,00,6$ & $*$ & 0,21 & $0,15-0,27$ & $*$ & 0,09 \\
\hline nuchtere glucose & 006 & 002044 & ns & 0,05 & $-0,01-0,11$ & & 0,05 \\
\hline hSCRPit & 0,16 & $0,08-024$ & 筆 & 0,15 & $0,09-0,21$ & $*$ & 0,27 \\
\hline \multicolumn{8}{|c|}{ odds ratio's and gs\% } \\
\hline Mets & 3,39 & $2,3,4,94$ & $\approx$ & 2,84 & $1,94-4,15$ & $a$ & \\
\hline
\end{tabular}

De analyses zijn gecorrigeerd voor leeftijd en geslacht. BMI = body mass index; SDS = standaarddeviatiescore.

"0,002 $<p<0,05 . " p<0,002 ; n s=$ niet significant,

a Loggetransformeerde variabelen: logtransformatie om normale verdeling zoveel mogelijk te benaderen.

b De onafhankelijke variabelen tussen geboorte en 18 jaar zijn conditionele maten, dus onafhankelijk van elkaar. Dit betekent dat deze variabele dát deel van de BMI SDS-verandering weergeeft in een bepaald leeftijdsinterval dat niet afhankelijk is van de voorafgaande BMI SDS(veranderingen). De formule om deze conditionele BMI SDS-veranderingen te verkrijgen is: $X_{\text {res } n}=Y-\alpha-\beta . Z_{0}-\gamma_{(n-\{(n-1))} \cdot X_{\text {res }\{n-(n-1)\}}-\gamma_{(n-\{n-2\})}$ $X_{\text {res }(n-\{n-2)\}}-\ldots . . .-\gamma_{(n-1)} . X_{\text {res }(n-1)}$, waarbij $Z_{0}=$ BMI SDS bij de geboorte, $X_{\text {res } n}$ conditional BMI SDS-veranderingen, en $Y$ de uitkomstvariabele. Als de kwadratische term van $X_{\text {res } n}$ significant was, werd deze ook toegevoegd aan de formule.

c verklaarde variantie van het model waarin alle BMI SDS-veranderingen als onafhankelijke variabelen zijn opgenomen.

vetdepositie die plaatsvindt vlak voordat het kind 6 jaar wordt, van belang is voor het ontwikkelen van overgewicht. Dit correspondeert met een gerelateerde vroege adipositas rebound (AR). Een vroege AR wordt geassocieerd met een verhoogd risico op overgewicht. ${ }^{22-23} \mathrm{De}$ gevonden relaties met cardiometabole risico's op jongvolwassen leeftijd stemmen in grote mate overeen met de resultaten van onderzoek binnen het New Delhi Birth Cohort. ${ }^{24}$

De sterke punten van onze studie zijn dat deze is uitgevoerd in een niet-geselecteerde populatie, en dat veel meetresultaten beschikbaar waren van bij de JGZ gepro- tocolleerde metingen van lengte en gewicht tussen de geboorte en de leeftijd van 14 jaar. Een beperking is dat we, net als in andere cohortstudies, te maken hadden met loss-to-follow-up; er was echter geen reden om aan te nemen dat de loss-to-follow-up gerelateerd is aan de gevonden relaties tussen BMI SDS-veranderingen op kinderleeftijd en de BMI SDS op volwassen leeftijd. Bovendien zijn er, met uitzondering van geslacht, geen verschillen gevonden in de baselinegegevens van de deelnemers aan de metingen en die van de oorspronkelijke populatie.

De resultaten van het Terneuzenonderzoek kunnen,

Tabel 2 De positief voorspellende waarde, sensitiviteit en specificiteit bij verschillende afkapwaarden van 2 voorspellingsmodellen om overgewicht op 23-jarige leeftijd te voorspellen met de BMI SDS op 2 leeftijden als onafhankelijke variabelen, namelijk voor het model met als leeftijdsinterval 2- tot 6-jarige leeftijd, en voor het model met leeftijdsinterval 2- tot 4-jarige leeftijd.

\begin{tabular}{|c|c|c|c|c|}
\hline \multicolumn{2}{|c|}{ afkapuarde wh de kaps op overgewicht } & \multirow[t]{2}{*}{$25 \%$} & \multirow[t]{2}{*}{$50 \%$} & \multirow[t]{2}{*}{$75 \%$} \\
\hline $\begin{array}{l}\text { voorspellingsmodel voor } \\
\text { het leeftidsinterval: }\end{array}$ & eigenschappen van het model: & & & \\
\hline $2-4$ jaar & positief voorspellende waarde & 0,49 & 0,58 & 0,94 \\
\hline $2-6$ jaar & & 0,52 & 0,67 & 0,86 \\
\hline $2 \cdot 4$ jaar & sensitiviteit & 0,75 & 0,28 & 0,08 \\
\hline 2.6 jaar & & 0,76 & 0,36 & 0,15 \\
\hline $2-4$ jaar & specificiteit. & 0,71 & 0,92 & 1,00 \\
\hline $2-6$ jaar & & 0,74 & 0,93 & 0,99 \\
\hline
\end{tabular}




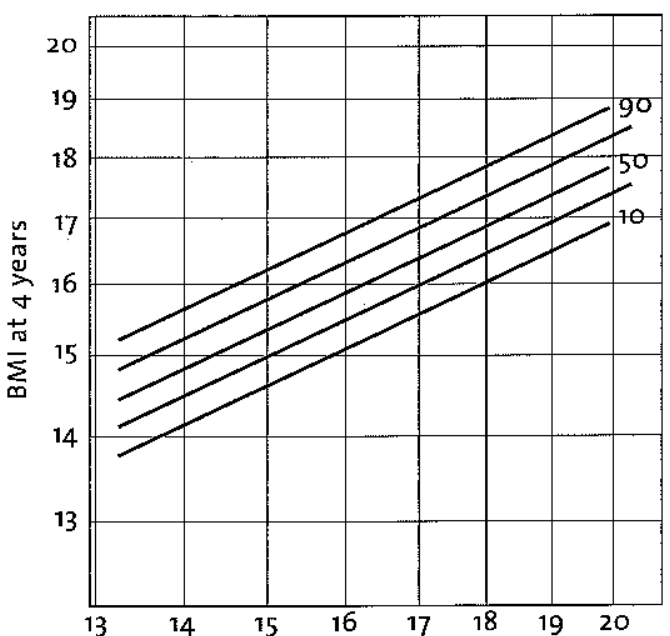

BMI at 2 years

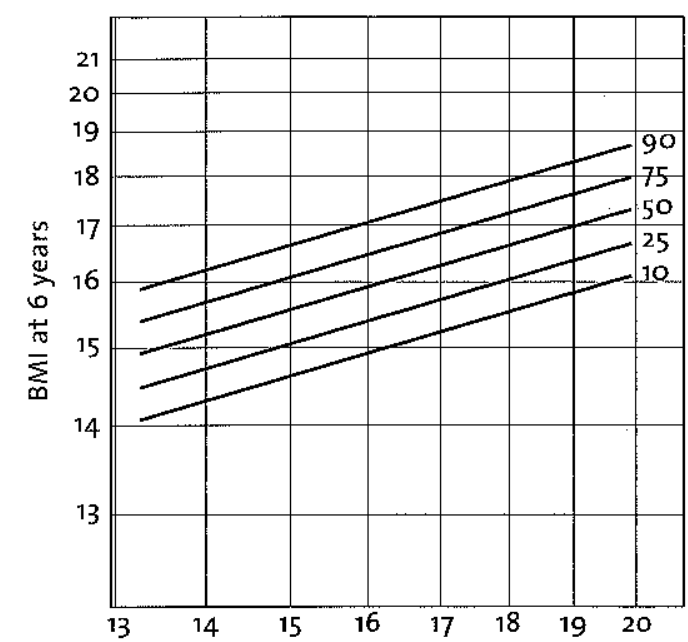

B

BMI at 2 years

Figuur 1 Risicoscorediagrammen voor jongens van wie de BMl gemeten is op 2-en 4-jarige leeftijd (A) en op 2- en 6-jarige leeftijd (B).

indien ze bevestigd worden in andere populaties, belangrijke praktische implicaties voor de JGZ hebben. Duidelijk is dat de JGZ speciale aandacht moet hebben voor een stijgende BMI SDS gedurende het leeftijdsinterval 2-6 jaar, ókk als een kind nog geen overgewicht heeft. Hiervoor is nodig dat predictie-instrumenten worden ontwikkeld.

Op dit moment wordt secundaire preventie aangeboden aan kinderen mét overgewicht. De in het Terneuzenonderzoek ontwikkelde prototypes van predictie-instrumenten bieden, na validatie en/of in combinatie met andere predictiemodellen zoals ontwikkeld in het PIAMA-cohort, de mogelijkheid om geïndiceerde primaire preventie aan te bieden. ${ }^{25}$ Met dergelijke predictieinstrumenten worden risicoschattingen gedaan, zodat preventieve interventies aangeboden kunnen worden aan diegenen die het hoogste risico hebben op overgewicht en cardiometabole ziekten en het dus het hardst nodig hebben. Hiermee kan de JGZ haar verbindende rol tussen universele en selectieve preventie aan de ene

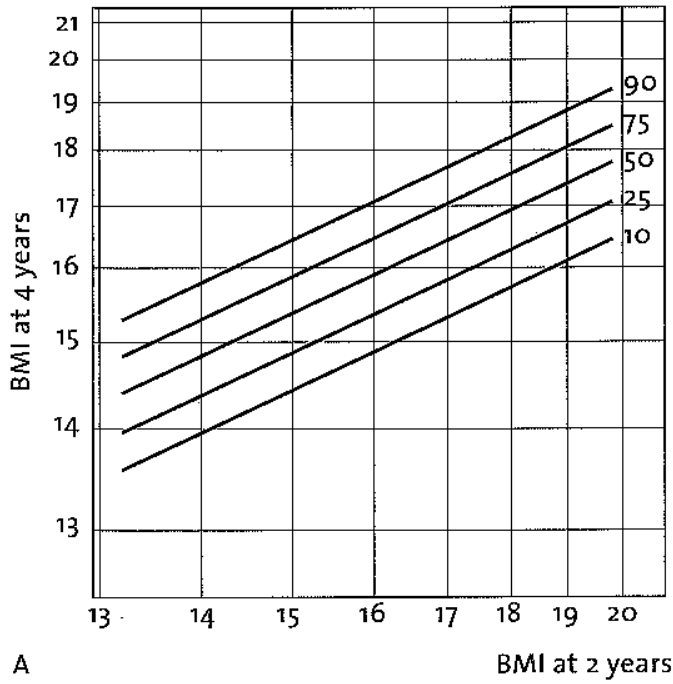

kant en individuele geïndiceerde preventieve zorg aan de andere kant als onderdeel van een integrale aanpak (zoals de JOGG-aanpak) van overgewicht en obesitas bij kinderen verder versterken.

Een predictie-instrument zoals ontwikkeld in het Terneuzen Geboorte Cohort zou een belangrijke ondersteuning kunnen bieden aan JGZ-professionals om gerichte primaire preventieve interventies aan te bieden. Het is immers ook gebleken dat het inzetten van predictie-instrumenten zoals de Strengths and Difficulties Questionnaire (SDO) de JGZ-professionals eerder aanzet tot een tijdige verwijzing dan de 'klinische blik' alleen. Gezien het grote bereik van de JGZ (meer dan;9\%\% van alle kinderen), biedt zij bij uitstek de mogelijkheid dergelijke predictie-instrumenten systematisch toe te passen. Bovendien kunnen deze instrumenten op termijn ingebouwd worden in het digitaal dossier van de JGZ om zo automatisch risicoschattingen te genereren.

De resultaten van het Terneuzen Onderzoek naar Preventie (TOP) vragen om speciale aandacht door de JGZ voor

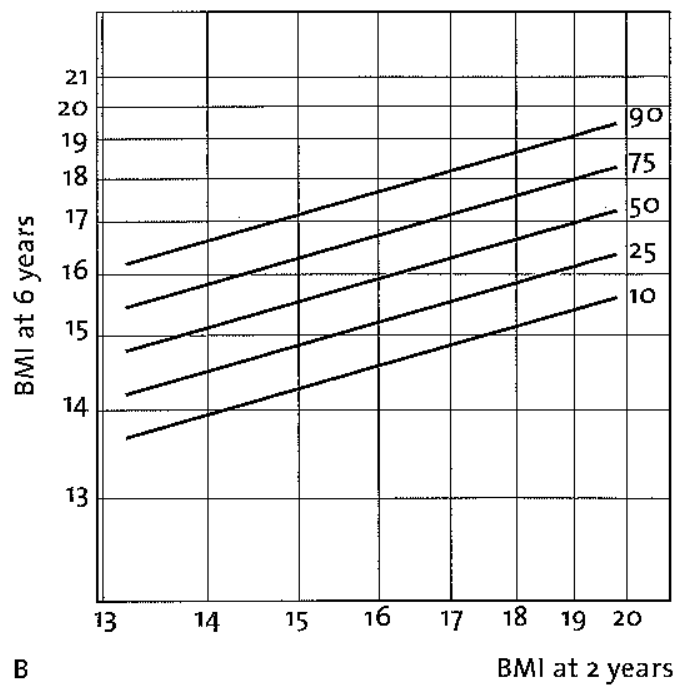

Figuur 2 Risicoscorediagrammen voor meisjes van wie de BMI gemeten is op 2-en 4-jarige leeftijd (A) en op 2-en 6-jarige leeftijd (B). 
een stijgende BMI SDS in het leeftijdsinterval 2-6 jaar, óok als er nog geen sprake is van overgewicht. Het monitoren en stabiliseren van de BMI SDS in dit leeftijdsinterval draagt mogelijk niet alleen bij aan de preventie van overgewicht op jongvolwassen leeftijd, maar ook aan een goede cardiometabole gezondheidstoestand op latere leeftijd.

\section{Literatuur}

1. Guh DP, Zhang W, Bansback N, Amarsi Z, Birmingham CL, Anis $\mathrm{AH}$. The incidence of co-morbidities related to obesity and overweight: a systematic review and meta-analysis. BMC Public Health. 2009;9:88.

2. Seidell JC. Obesity, insulin resistance and diabetes - a world wide epidemic. Br J Nutr. 2000;83 Suppl 1: $5_{5}-\mathrm{S} 8$.

3. Schönbeck Y, Talma H, Dommelen P van, Bakker B, Buitendijk SE, Hirasing RA, e.a. Increase in prevalence of overweight in Dutch children and adolescents: a comparison of nationwide growth studies in 1980, 1997 and 2009. Plos One 2011;6(11):e27608.

4. Veldhuis L, Vogel I, Renders CM, Rossem L van, Oenema A, Hirasing RA, e.a. Behavioral risk factors for overweight in early childhood; the 'Be active, eat right' study. Int J Behav Nutr Phys Act. 2012;15;9:74.

5. Raat H. www.zonmw.nl/nl/projecten/project-detail/evaluation-of-the-dutch-preventive-youth-health-care-yhc-overweight-prevention-protocol-and-overwe/voortgang/ 2011.

6. Kroon MLA de, Marlou LA. The Terneuzen Birth Cohort. Detection and prevention of overweight and cardiometabolic risk from infancy onward. Thesis. Amsterdam: Vrije Universiteit; 2011.

7. Kroon ML de, Renders CM, Wouwe JP van, Buuren S van, Hirasing RA. The Terneuzen birth cohort: BMI changes between 2 and 6 years correlate strongest with adult overweight. PLoS One. 2010;5(2):e9155

8. Kroon ML de, Renders CM, Wouwe JP van, Buuren S van, Hirasing RA. The Terneuzen Birth Cohort: BMI change between 2 and 6 years is most predictive of adult cardiometabolic risk. PLoS One. 2010;5(11):e13966.

9. Kroon ML de, Renders CM, Wouwe JP van, Hirasing RA, Buuren $S$ van. Identifying Young children without overweight at high risk of adult overweight: The Terneuzen Birth Cohort. Int J Ped Obes. 2011 Jun;6(2-2):e187-95

10. Kroon ML de, Renders CM, Kuipers EC, e.a. Identifying metabolic syndrome without blood tests in young adults - the Terneuzen Birth Cohort. Eur J Public Health. 2008;18(6):65660.

11. Monteiro PO, Victora CG. Rapid growth in infancy and childhood and obesity in later life - a systematic review. Obes Rev. 2005;6(2):143-54.

12. Kvaavik E, Tell GS, Klepp KI. Predictors and tracking of body mass index from adolescence into adulthood: follow-up of 18 to 20 years in the Oslo Youth Study. Arch Pediatr Adolesc Med. 2003;157(12):1212-8.
13. Ong KK, Ahmed ML, Emmett PM, Preece MA, Dunger DB. Association between postnatal catch-up growth and obesity in childhood; prospective cohort study. BMJ. 2000;320(7240):967-71.

14. Stettler N, Stallings VA, Troxel AB, Zhao J, Schinnar R, Nelson SE, e.a. Weight gain in the first week of life and overweight in adulthood: a cohort study of European American subjects fed infant formula. Circulation 2005;111(15):1897-903.

15. Scholtens S, Gehring U, Brunekreef B, Smit HA, Jongste IC de, Kerkhof M, Gerritsen J, Wijga AH. Breastfeeding, weight gain in infancy, and overweight at seven years of age: the prevention and incidence of asthma and mite allergy birth cohort study. Am J Epidemiol. 2007;165(8):919-26.

16. Oren A, Vos LE, Uiterwaal CS, Gorissen WH, Grobbee DE, Bots ML. Change in body mass index from adolescence to young adulthood and increased carotid intima-media thickness at 28 years of age: the Atherosclerosis Risk in Young Adults study. Int I Obes Relat Metab Disord. 2003;27(11):1383-90.

17. Botton J, Heude B, Maccario J, Ducimetiere P, Charles MA Postnatal weight and height growth velocities at different ages between birth and $5 \mathrm{y}$ and body composition in adolescent boys and girls. Am J Clin Nutr. 2008;87(6):1760-8.

18. Kindblom JM, Lorentzon M, Hellqvist A, Lönn L, Brandberg J, Nilsson S, e.a. BMI changes during childhood and adolescence as predictors of amount of adult subcutaneous and visceral adipose tissue in men: the GOOD Study. Diabetes. 2009;58(4):867-74.

19. Sachdev HS, Fall CH, Osmond C, Lakshmy R, Dey Biswas SK, Leary SD, e.a. Anthropometric indicators of body composition in young adults: relation to size at birth and serial measurements of body mass index in childhood in the New Delhi birth cohort. Am J Clin Nutr. 2005;82(2):456-66.

20. Vogels N, Posthumus DL, Mariman EC, Bouwman F, Kester AD, Rump P, e.a. Determinants of overweight in a cohort of Dutch children. Am J Clin Nutr. 2006;84(4):717-24.

21. Martorell R. Results and implications of the INCAP follow-up study. J Nutr. 1995;125(4 Suppl):1127S-38S

22. Baird J, Fisher D, Lucas P, Kleijnen J, Roberts H, Law C. Being big or growing fast: systematic review of size and growth in infancy and later obesity. BM. 2005;331(7522):929.

23. Cole TJ. Children grow and horses race: is the adiposity rebound a critical period for later obesity? BMCPediatr. 2004;4:6.

24. Fall CH, Sachdev HS, Osmond C, Lakshmy R, Biswas SD, Prabhakaran D, e.a. Adult metabolic syndrome and impaired glucose tolerance are associated with different patterns of BMI gain during infancy: Data from the New Delhi Birth Cohort. Diabetes Care. 2008;31(12):2349-56.

25. Steur M, Smit HA, Schipper CM, Scholtens S, Kerkhof M, Jong ste JC de, e.a. Predicting the risk of newborn children to become overweight in later childhood. The PIAMA birth cohort study. Int je Ped Obesity. 2011;6(2-2):e170-8. 